\section{穴 Heighten Science \\ P U B L I C I T I O N S Corporation ISSN 2575-0186}

\title{
Brain changes in Hypothermia: Surface-versus Core-cooling in pigs
}

\author{
Stig Morten Hammersborg ${ }^{1,2}$, Paul Husby ${ }^{1,2}$, Inge Morildd ${ }^{3,4 *}$ and \\ Peer Kåre Lilleng ${ }^{3,4}$ \\ 'Departement of Anaesthesia and Intensive care, Haukeland University Hospital, Norway \\ ${ }^{2}$ Department of Clinical Science, University of Bergen, Norway \\ ${ }^{3}$ Gade Laboratory for Pathology, Department of Clinical Medicine, University of Bergen, Norway \\ ${ }^{4}$ Department of Pathology, Haukeland University Hospital, 5021 Bergen, Norway
}

\footnotetext{
*Address for Correspondence: Inge Morild, Gade Laboratory for Pathology, Department of Clinical Medicine, University of Bergen, Norway, Tel: +47 559725 60; Fax: +4755975139; Email:

inge.morild@uib.no;inge.morild@helse-bergen.no

Submitted: 25 October 2017

Approved: 30 October 2017

Published: 31 October 2017
}

Copyright: @ 2017 Hammersborg SM, et al. This is an open access article distributed under the Creative Commons Attribution License, which permits unrestricted use, distribution, and reproduction in any medium, provided the original work is properly cited.

Keywords: Hypothermia; Surface cooling; Core cooling; Pigs; Histopathology; Aseptic meningitis Cerebral micro dialysis

\section{Abstract}

The process of hypothermia in the clinical setting has been practiced for 50 years and is known for its neuroprotective properties. This paper describes histopathological changes either by an ice sludge mimicking accidental hypothermia ( $\mathrm{S}$-group $\mathrm{n}=7$ ) or by endovascular core-cooling (C-group $\mathrm{n}=7$ ). Focal infiltrates of neutrophilic granulocytes were found in five of seven brains in the S-group and in one of seven brains in the C-group. These granulocytes were found in the arachnoids, in vessels, in vessel walls, and in the cerebral cortex. Fungi, bacteria, lymphocytes or plasma were not found.

This experimental study, mimicking accidental hypothermia, reported histopathologic features of aseptic inflammation. To our knowledge, such findings have not been described in hypothermic animals or humans before. We suggest that a local inflammatory response may be triggered in such cases of hypothermia.

\section{Introduction}

The process of hypothermia was introduced in clinical practice more than 50 years ago, as a neuroprotectant during open heart surgery, to enable procedures with the potential of prolonged ischemia. During the last decade this has been reintroduced to treatment protocols of cardiac arrest after myocardial infarction and in the handling of stroke. Induced mild hypothermia $\left(34-35^{\circ} \mathrm{C}\right)$, has significantly contributed to improve the outcome of these conditions. Hypothermia slows down cellular metabolism, oxygen demand, and preserves the cellular energy level $[1,2]$. In addition, hypothermia has the capability to modulate abnormal cellular free radical production, and to prevent intracellular acidosis by preservation of membrane integrity, ion-pump- and mitochondrial function during early ischemia. Similarly, hypothermia modulates necrotic, apoptotic and inflammatory pathways during the reperfusion period [3].

Despite these positive, tissue preserving effects, hypothermia has some undesirable side effects. Hypothermia increases fluid extravasation $[4,5]$ and thereby contributes to plasma volume contraction, hemoconcentration, and intravascular cell aggregation that may result in micro vascular stasis, perivascular edema, hypoperfusion and at the end tissue ischemia [6,7].

In a previous study of pigs cooled to deep and stable, prolonged hypothermia by different cooling techniques, we observed a decrease in plasma volume, hemoconcentration and significant increase in fluid- and protein extravasation, independent of the cooling technique. The extravasation fluid resembled whole plasma, and resulted in tissue edema that affected a number of vital organs. We hypothesized that inflammatory mechanisms could be involved in the increase of microvascular permeability during hypothermia [8]. Based on our previous findings, this study was undertaken to study the possible morphological effects in the organs of hypothermic pigs. 


\section{Materials and Methods}

Fourteen immature domestic pigs (Norwegian landrace Norhybrid, Stend Agricultural College, Norway) were studied. Handling of the animals was in accordance with recommendations given by the Norwegian Animal Research Authority. Food was withdrawn 12 hours prior to the experiments, whereas water was provided at all times.

The animals were randomly allocated to the S-group (surface cooling) or the C-group (core cooling). In addition, two normothermic pigs were used as controls for histopathological studies. Medication and anaesthesia including measuring of ventilation, temperature, blood pressure, heart rate, and the surgical preparation prior to and during the experiments are thoroughly described [8]. A heat exchange catheter was inserted into the vena cava inferior vein the animals of both groups, and used for application of endovascular core-cooling and maintenance of stable hypothermia in the C-group, whereas the catheter remained inactivated in the S-group. Intracranial pressure (ICP) and cerebral metabolism, with focus on changes in cerebral glucose-, lactate-, pyruvate-, and glycerol-concentration in the first five animals in both groups, was measured from intracerebral catheters through burr holes in the pigs' skull, dura mater was incised with surgical diathermy and the bone defects were plugged with bone wax (Ethicon Bone Wax, W810, Johnson \& Johnson company, Lot: XJ5BKKC, 2011-12). Heart rate was obtained by use of surface ECG electrodes. Systemic arterial pressures were monitored continuously together with central venous pressure via intravascular catheters in the right femoral artery, in the vein, and in the pulmonary artery. Skin-scratches were made on the abdomen and the scratches exposed to bone wax, to examine allergic or inflammatory effects due to the wax.

After the surgical procedures the pigs were brought to normothermic stabilization for 60 minutes before the initiation of cooling. The pigs in the S-group were draped in waterproof blankets and placed in ice sludge (temperature of $0-0.5 \div 0$ ). When the core temperature approached $29.0^{\circ} \mathrm{C}$ the cooling procedure was terminated and the animals moved to room temperature and stabilized. In the pigs of the C-group, central cooling was performed via a heat exchange catheter connected to a cool machine (Cool Guard ${ }^{\circledR}$ model 2050 Research Machine, from Alsius Corporation, Canada, USA). The cooling catheter was perfused with acetated Ringer's solution with a temperature of $0.5-2.0^{\circ} \mathrm{C}$ resulting in an initial cooling rate similar to the rate during surface cooling in ice sludge. The animals were sacrificed with intravenous injection of $20 \mathrm{ml}$ saturated potassium chloride solution, at the end of each experiment [8].

\section{Tissue samples and preparation}

After death, autopsy was performed; tissue samples were collected from all organs and from abdominal skin, where bone wax had been applied to scratches. The brain was removed and all tissue was fixed in $4 \%$ formaldehyde. Brain tissue was obtained from the anterior pole on both sides, central areas with the basal ganglia, both occipital lobes, cerebellum including vermis and from pons. The material was paraffin embedded, sliced in $3 \mu \mathrm{m}$ thick sections and stained with haematoxylin and eosin. Samples from the brain were also stained with luxol fast blue, PAS and Gram's staining method and immunohistochemistry performed. Microscopy of the slides was done by all the authors, including the two pathologists.

\section{Statistics}

The data were analyzed by use of SPSS version 13.0 for Windows. Repeated measure analysis of variance with one grouping variable was used to test the relationship of outcome variables at different times. When a significant between-group P-value was found, post-hoc t-tests were performed to compare the data 60 minutes before cooling and 180 minutes after initiation of cooling (i.e. at $240 \mathrm{~min}$ ). The level of significance was defined as $\mathrm{P}<0.05$. The $\mathrm{P}$-value was adjusted according to the number of comparisons. The mean and standard deviation (SD) for all data were estimated. 


\section{Results}

The animals of the study groups were comparable with respect to age: 75.0 (10.6) and 76.4 (14.3) days; weight: 24.9 (2.3) and 25.1 (3.9) kg; and gender: M/F: 3/5 and 4/3; S-versus C-group, respectively. Soon after start of cooling, the body core temperature decreased similarly in both study groups. After the animals of the S-group were removed from the ice sludge they subsequently had a drop in core temperature, resulting in lower temperature $\left(25.9(0.6)^{\circ} \mathrm{C}\right)$ compared with the C-group $\left(27.9(0.4)^{\circ} \mathrm{C}\right)$, at the end of the hypothermic period. Mean arterial pressure (MAP) and cerebral perfusion pressure (CPP) decreased in both groups throughout the hypothermic period. No significant between group differences were noted. Cerebral micro dialysis was performed in the first five experiments of each group. Lactate/Pyruvate ratio (L/P-ratio) and cerebral glycerol concentration remained within normal range during the study. Cerebral glucose concentration decreased significantly in the S-group, but not in the C-group. The C-group values tended, however, to stay below the S-group values at most time intervals studied.

\section{Histopathological findings}

Focal infiltrates of neutrophilic granulocytes were found in five of the seven pigs cooled in ice sludge and in one of the seven core-cooled pigs. The granulocytes were found in the arachnoids, in vessels, in vessel walls, and in three cases also in the cortex (Figures 1,2). The PAS staining showed no fungi and Gram's staining showed no bacteria. Lymphocytes or plasma cells were not present in the infiltrates (immunohistochemistry). The findings were limited to the cerebrum, no such infiltrates were found in the trepanation-area, along the channel from the ICP-catheter, cerebellum or in the pons. There were no signs of inflammation in the abdominal skin scratches exposed to bone wax. Except from general congestion in the lungs no pathology was found in the other organs. The two control pigs had no histopathological findings.
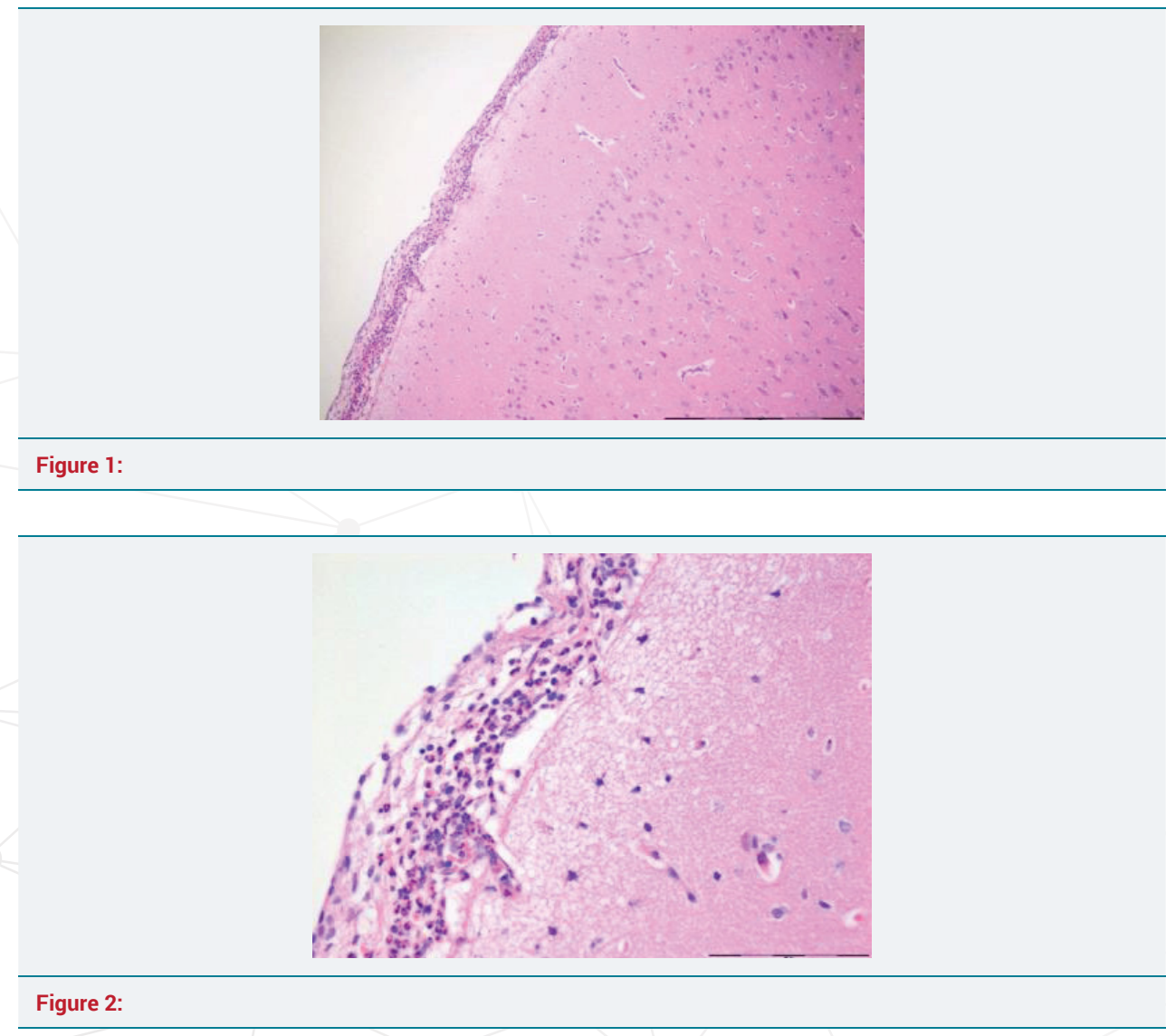


\section{Discussion}

The organ preserving effect of hypothermia has been linked to its ability to slow down cellular metabolism, to reduce oxygen demand while maintaining the cellular ATP energy level $[2,3]$. Mechanisms that may modulate metabolism, abnormal cellular free radical production, as well as pathways contributing to cellular damage/cell death during reperfusion after an ischemic event has been described [3].

Hypothermia has been used in clinical practice for decades to enable surgical procedures associated with risk of tissue and organ ischemia. In more recent time hypothermia has been reintroduced to clinical practice as "therapeutic hypothermia" in the handling of cardiac victims after myocardial infarction [9]. Its use has significantly contributed to improve the outcome. Therapeutic hypothermia has also been proposed in cases of severe traumatic brain injury and stroke because of its ability to reduce intracranial pressure and the putative neuroprotective effects [10-13]. In the latter two conditions the use of therapeutic hypothermia is still uncertain.

Despite a number of favorable properties of hypothermia, its use is limited due to a number of adverse side effects. An increase in microvascular permeability by hypothermia results in fluid-and protein-shifts from the intravascular to the interstitial compartment, with formation of tissue edema that occasionally contribute to heart-, lung- and gastrointestinal organ dysfunction $[5,6,14]$. In the present study no fluid was given during the experiments. The consequences of such a strategy, mimicking accidental hypothermia, is marked hemoconcentration, intravascular cell aggregation, formation of perivascular edema and microcirculatory deterioration, and at the end ischemia. These changes relates not only to the duration of hypothermia, but also to the temperature level [6]. This may be the explanation of why the histopathological changes were more frequently observed in the surface cooled-, than in central-cooled pigs. In the surface cooled pigs the shell temperature dropped to levels below $5{ }^{\circ} \mathrm{C}$ and may have caused a near-freezing cold injury with endothelial disruption and ultrastructural changes resembling ischemia/reperfusion injuries, as described by Endrich et al. [8].

The increase in extravasation of both water and proteins, with a composition similar to whole plasma, observed in earlier research [8] led to one question: Could inflammatory mechanisms be involved? In this evaluation we found noteworthy changes in the brains. There were infiltrates of neutrophilic granulocytes in the brains of five pigs cooled to deep hypothermia in ice sludge (S-group) and in one of the pigs cooled by an intravascular cooling catheter (C-group). Neither fungi nor bacteria were found.

The analysis of hemodynamic parameters including MAP and CPP, could explain possible hypoperfusion, at least during the last period of the experiments, in the animals of the surface-cooled group. Haugen et al. [15], found biochemical and morphologic changes consistent with hypoperfusion and anaerobic metabolism when MAP decreased below $40 \mathrm{mmHg}$ and CPP below $30 \mathrm{mmHg}$ during hypothermic $\left(28^{\circ} \mathrm{C}\right)$ cardiopulmonary bypass. In the present study, however, the L/P-ratio remained within normal range. Hypoperfusion seems therefore unlikely. The low cerebral glycerol concentration obtained from cerebral microdialysate further support adequate perfusion with maintained cerebral cellular integrity. Finally, the histopathological findings in the brains examined, were present not only in the surface-cooled animals, but also in one of the core-cooled pigs with higher MAP and CPP values. Depletion of substrates for generation of high-energy phosphates initiates a cascade of metabolic events leading to neuronal death [16]. In our study the normal lactate/pyruvate ratio and glycerol concentration makes adequate glucose supply reasonable. The normal s-glucose concentration for the domestic pigs in our experiments was $4.6 \mathrm{mmol} / \mathrm{L}$ with a range from 2.6 to $6.5 \mathrm{mmol} / \mathrm{L}$ [17]. 
The focal granulocyte infiltrates observed more frequently in the brain of surface cooled pigs, were present in both hemispheres of the cerebrum. Our results are in contrast to other publications $[18,19]$, where such histopathological changes in the brains of small/newborn piglets following cooling and mild hypothermia were absent. Other investigators have focused on reduced granulocyte infiltration in induced brain inflammation following mild hypothermia [20]. In our next project we will focus on micro vascular perfusion during profound hypothermia and the following inflammatory process in the brain of pigs. Furthermore, we hope to investigate possible inflammation in the brains of humans, dying from hypothermia.

\section{References}

1. Eisenburger $P$, Sterz $F$, Holzer $M$, Zeiner A, Scheinecker $W$, et al. Therapeutic hypothermia after cardiac arrest. Curr Opin Crit Care. 2001; 7: 184-188. Ref.: https://goo.gl/brTWx9

2. Nilsson L, Kogure K, Busto R. Effects of hypothermia and hyperthermia on brain energy metabolism. Acta Anaesthesiol Scand. 1975; 19: 199-205. Ref.: https://goo.gl/iD6LGH

3. Moore EM, Nichol AD, Bernard SA, Bellomo R. Therapeutic hypothermia: benefits, mechanisms and potential clinical applications in neurological, cardiac and kidney injury. Injury. 2011; 42: 843-854. Ref.: https://goo.gl/eBMjSu

4. Hammersborg SM, Farstad M, Haugen O, Kvalheim V, Onarheim $\mathrm{H}$, et al. Time course variations of haemodynamics, plasma volume and microvascular fluid exchange following surface cooling: an experimental approach to accidental hypothermia. Resuscitation. 2005; 65: 211-219. Ref.: https://goo.gl/6jYLBi

5. Farstad M, Heltne JK, Rynning SE, Lund T, Mongstad A, et al. Fluid extravasation during cardiopulmonary bypass in piglets-effects of hypothermia and different cooling protocols. Acta Anaesthesiol Scand. 2003; 47: 397-406. Ref.: https://goo.gl/a4xDMx

6. Lofstrom B. Induced hypothermia and intravascular aggregation. Acta Anaesthesiol Scand. 1959; 3 : 1-19. Ref.: https://goo.gl/4qiox3

7. Endrich B, Hammersen F, Messmer K. Microvascular ultrastructure in non-freezing cold injuries. Res Exp Med. 1990; 190: 365-379. Ref.: https://goo.gl/L2hLA1

8. Hammersborg SM, Brekke HK, Haugen O, Farstad M, Husby P. Surface cooling versus core cooling comparative studies of microvascular fluid- and protein-shifts in a porcine model. Resuscitation. 2008; 79: 292-300. Ref.: https://goo.gl/pxxLXa

9. Schwartz BG, Kloner RA, Thomas JL, Bui Q, Mayeda GS, et al. Therapeutic Hypothermia for Acute Myocardial Infarction and Cardiac Arrest. Am J Cardiol. 2012; 110: 461-466. Ref.: https://goo.gl/31 wyyk

10. Kramer C, Freeman WD, Larson JS, Hoffman-Snyder C, Wellik KE, et al. Therapeutic hypothermia for severe traumatic brain injury: a critically appraised topic. Neurologist. 2012; 18: 173-177. Ref.: https://goo.gl/VwGsvx

11. Lakhan SE, Pamplona F. Application of mild therapeutic hypothermia on stroke: a systematic review and meta-analysis. Stroke Res Treat. 2012. Ref.: https://goo.gl/odrzQF

12. Lampe JW, Becker LB. State of the art in therapeutic hypothermia. Annu Rev Med. 2011; 62: 79-93. Ref.: https://goo.gl/ufJWiA

13. Delhaye C, Mahmoudi M, Waksman R. Hypothermia therapy: neurological and cardiac benefits. J Am Coll Cardiol. 2012; 59: 197-210. Ref.: https://goo.gl/x4hqv7

14. Kvalheim VL, Farstad M, Steien E, Mongstad A, Borge BA, et al. Infusion of hypertonic saline/starch during cardiopulmonary bypass reduces fluid overload and may impact cardiac function. Acta Anaesthesiol Scand. 2010; 54: 485-493. Ref.: https://goo.gl/Vx5uUm

15. Haugen O, Farstad M, Myklebust R, Kvalheim V, Hammersborg S, et al. Low perfusion pressure during CPB may induce cerebral metabolic and ultrastructural changes. Scand Cardiovasc J. 2007; 41: 331-338. Ref.: https://goo.gl/n4mkHJ

16. Lemasters JJ, Theruvath TP, Zhong Z, Nieminen AL. Mitochondrial calcium and the permeability transition in cell death. Biochim Biophys Acta. 2009; 1787: 1395-401. Ref.: https://goo.gl/XKEoKv

17. Hannon JP, Bossone CA, Wade CE. Normal physiological values for conscious pigs used in biomedical research. Lab Anim Sci. 1990; 40: 293-298. Ref.: https://goo.gl/zEz9gT 
18. Iwata O, Iwata S, Tamura M, Nakamura T, Sugiura M, et al. Early head cooling in newborn piglets is neuroprotective even in the absence of profound systemic hypothermia. Pediatr Int. 2003; 45: 522529. Ref.: https://goo.gl/zVEcvG

19. Iwata S, Iwata 0 , Thornton JS, Shanmugalingam S, Bainbridge A, et al. Superficial brain is cooler in small piglets: neonatal hypothermia implications. Ann Neurol. 2006; 60: 578-585. Ref.: https://goo.gl/mQQNNh

20. Prandini MN, Neves Filho A, Lapa AJ, Stavale JN. Mild hypothermia reduces polymorphonuclear leukocytes infiltration in induced brain inflammation. Arq Neuropsiquiatr. 2005; 63: 779-784. Ref.: https://goo.gl/xnAiHd 